\title{
América Latina y la CEE: ¿De la separación al divorcio?*
}

\author{
Joaquin Arriola Palomares \\ Koldo Unceta Satrústegui
}

\section{La CEE, mitos y realidades.}

El proyecto de un mercado interior circunscrito a Europa Occidental debe ser analizado desde una adecuada perspectiva histórica y metodologica: primeramente la historia del capitalismo en general y del capital de los paises europeos en particular; y en segundo término, la metodología que nos permita situar la evolución más reciente y el marco de la "Europa-92" en el contexto más amplio de la contradicción entre los procesos de centralización y concentración del capital por una parte y la constitución nacional de los capitales por otra. Esta es la contradicción que ha marcado la historia del siglo XX en Europa, y que se sitúa en el transfondo de los acontecimientos más significativos de la misma: la revolución rusa, las dos guerras mundiales, y la sustitución de Gran Bretana por los EE.UU. como nación hegemónica a escala del capitalismo mundial son fenómenos cuya influencia en los orígenes y configuración actual -y previsiblemente futura- de la Comunidad Económica Europea es más importante de to que muchos análisis dejan ver.

- Una versión anterior de este trabajo se presentó como potencial en el Seminario del CREAL. (Concertación para las Relaciones entre Europa y América Latina) en Chantilly (Francia), 29 febrero-2 marzo 1990. 
1.1 La CEE como sintesis de los capltales europeos frente al capltal de los EE. UU.

El proyecto de un mercado capitalista europeo se apunta "in nuce" a finales del siglo $X \mid X$ : En medio de la guerra francoprusiana, la constitución de la Comuna de París, cuando Bismarck libera a prisioneros franceses para que apaguen el fuego de la revuelta obrera, o la Conferencia de Berlin de 1885, en que se deciden las reglas del juego y las compensaciones a otorgar a las potencias que no participan en el reparto de las colonias', son dos claros síntomas de la "colaboración de clase" y de la conciencia de ocupar un espacio social y político común, al margen de la persistencia de las rivalidades nacionales.

Esta cooperación entre los capitales europeos o sus representantes políticos tampoco quedó interrumpida con la primera guerra mundial. Cuando la firma alemana Krupp, habiendo cedido una licencia a la británica Vickers para la fabricación de su excelente espoleta de obús, se encuentra con la declaración de guerra, deciden utilizar como medida para calcular los beneficios a trasferir no el número de obuses fabricados - secreto de guerra- sino los soldados alemanes muertos en campo británico: seis anos después del final de la guerra. Vickers pagó las tres libras esterlinas por soldado acordadas a su socio alemán. ${ }^{2}$

También es larga la historia de los flujos de capital entre países europeos: en 1914, las inversiones francesas de capital a largo plazo en Europa representaban el $61.1 \%$ de sus inversiones en el extranjero, y un $53.2 \%$ las de Alemania. Tan solo Gran Bretana destinaba en la época un porcentaje superior a las inversiones en ultramar: $\mathbf{4 7 . 3 \%}$ en las colonias y $\mathbf{2 0 . 1 \%}$ en los Estados Unidos. ${ }^{3}$ No es casual el desapego tradicional de Gran Bretana respecto a la construcción de la CEE: es un claro reflejo de la vocación ultramarina del capital inglés, demostrada a to largo de toda su historia. Las inversiones británica de capital en Europa fueron un 25\% del total en el período $1860-1870,22 \%$ en $1881-1890,6 \%$ en 1911 $1913,8 \%$ en $1927-1929,8.5 \%$ en $1955-59,14 \%$ en 1970.4

\footnotetext{
1. Afrique Asie num. 342, febrero-marzo 1985.

2. Winfried Wolf: Siebzehn Thesen zum Proyekt westeuropäische Binnenmark en Jutta Kalss (eda.) p. 16-17.

3. Datos elaborados a partir de David K. Fieldhouse: Economía e Imperio Siglo XXI, Madrid 1977 pp. 66-70.

4. Michael Barrat Brown: La teorla económica del imperialismo Alianza Editorial, Madrid 1975 pp. 198-199.
} 
Omitimos el relato histórico, pero queremos dejar sentado que cuando en el 25 de marzo de 1957 se firma el Tratado de Roma, existe ya una larga tradición de cooperación - lo mismo que de enfrentamientos- entre los capitales europeos.

Cuando a principios de junio de 1955 se reunieron en Messina los ministros de Asuntos exteriores de los Seis, anunciaron que querian promover "el establecimiento de una Europa unida para mantener a Europa en el lugar que ocupa en el mundo, para devolverle su influencia y su gloria y para aumentar de manera continua el nivel de vida de su pueblo". ${ }^{5}$ Estas palabras nos sitúan en el contexto real en que se establece la Comunidad: el final de la II GM, y el primer proyecto ideado por los Estados Unidos -"Plan Morgenthau" - que pretendia hacer retroceder a Alemania al nivel de un pais agrario.

La demanda de independencia de las colonias, las revoluciones China y la Guerra de Corea, son elementos importantes en el desencadenamiento de la Guerra Fría. La voluntad de recuperar la Europa del Este para el mercado capitalista, lleva a implementar el Plan Marshall, tendente a estabilizar la situación económica de la Europa occidental, convirtiéndola en un baluarte económico y militar frente a la influencia soviética en Europa. No es casualidad que casi simultaneamente a la constitución de la CECA, se proponga la creación de la Comunidad Europea de Defensa (CED), tendente a una integración de los ejércitos europeos, cuyo fracaso se sitúa tanto en las divergencias entre las políticas exteriores de los paises implicados como en la voluntad de los Estados Unidos de mantener la política de defensa de sus aliados europeos bajo el paraguas de la OTAN. Como tampoco lo es que el Consejo de Ministros de la CEE proponga a Gran Bretańa en julio de 1963 contactos regulares... en el marco militar de la Unión de Europa Occidental, justo 6 meses después de que se interrumpiesen las negociaciones sobre su posible incorporación a la Comunidad.

El Plan Werner para la unión económica y monetaria fija a fines de 1970 la fecha de 1980 como momento de la completud de la misma. El retraso de 12 ańos hasta 1992 es consecuencia por una parte de la crisis del sistema monetario internacional desencadenada en 1971, pero también de las propias rivalidades entre los capitales de los diferentes paises comunitarios, que lejos de haberse unificado se encuentran lejos de constituir un "capitalismo europeo"

5. Etapas de Europa - Cronología de la Comunidad Europea, p. 14. 
como tal, que responda a un modo de regulación único, aunque el régimen de acumulación esté ciertamente cohesionado a escala comunitaria. De hecho, si algún capital tiene una estrategia estrictamente europea o comunitaria, seria el capital transnacional de origen norteamericano, presente en Buselas con un número de empleados de multinacionales USA superior al de funcionarios de la Comunidad.

\subsection{La jerarquia de Intereses naclonales en el funclonamlento de la CEE.}

La contradictoria trayectoria de la integración tanto sociopolítica como económica de la Europa Occidental se refleja en la preponderancia de los intereses de los países integrantes en las decisiones comunitarias.

Sin hacer verdadero el dicho de que "quien paga, manda", en las estructuras de la CEE, desde su constitución, se establece un complejo sistema de influencias relativas desiguales, que si por un lado es consecuencia del diferente peso económico y social de los miembros integrantes de la Comunidad (la RFA, con menos de la quinta parte de la población comunitaria, representa más de la cuarta parte del PIB conjunto; un ciudadano danés dispone de la renta de seis portugueses), ${ }^{\circ}$ por otra parte responde a los condicionamientos políticos con que se crea la CEE. Francia y la R. F. de Alemania, a pesar del enfrentamiento histórico que libran hasta la II Guerra Mundial, en el clima de la Guerra Fría se convierten en los principales pilares de la construcción de la Comunidad. Los lazos históricos y culturales de Gran Bretana con los EE.UU se manifiestan también en las diferencias de comportamiento de los capitales británicos respecto a los franceses y germanos: éstos, más interesados en el mercado europeo, mientras aquél se reparte entre las actividades financieras vinculadas a la City y los mercados norteamericanos y de los paises de la Commonwealth. Asl, no sólo la tardia incorporación británica contribuye al menor específico de este país en la CEE, sino que el interés del capital británico es también menor que el de los capitales alemanes, franceses o italianos en el proyecto del mercado único.

Ejemplos de esta hegemonia franco-gemana, son la nptura de las negociaciones ante la duda manifestada por el presidente de Gau-

- Datos obtenidos en Banco Mundial: Informe sobre el Desarrollo Mundial 1989. 
lle sobre la voluntad de adhesión de Gran Bretaña en 1963; o ॥l freno impuesto por el propio De Gaulle en 1965 al proceso de in tegración creando una crisis en la comunidad. O que el Sistema Monetario Europeo no termine de alumbrar una moneda europea, por las reticencias de algunos paises ante lo que seria la creación básicamente de una moneda comunitaria en la cual la influencia principal seria la de la R. F. de Alemania; o la PAC, que ha contribuido a reproducir durante varias décadas unas estructuras agricolas no competitivas, sobre todo en Francia, absorbiendo casi cuatro quintas partes del presupuesto comunitario.

\subsection{Las relaciones de la CEE con el Tercer Mundo como reflejo de dicha jerarquia}

Cuando se firma el Tratado de Roma en 1957, se tuvo en cuenta a aquellas áreas del Tercer Mundo vinculadas a los paises signatarios: los territorios franceses en Africa, el Congo Belga, Rwanda y Burundi (bajo administración belga) y Somalia (bajo administración italiana). En 1963, se firma el Convenio de Yaoundé con los paises africanos que mantienen relaciones históricas con algún pais ex colonialista miembro de la comunidad: los intentos de Kenia, Uganda y Tanganika (de influencia británica) por establecer relaciones con la Comunidad no fructifican hasta 1973, cuando con la incorporación a la Comunidad a Gran Bretaña, se amplia el interés de la CEE por el Tercer Mundo, en este caso hacia los países miembros de la Commonwealth.

Las relaciones económicas con el Tercer Mundo, globalmente consideradas, no cuentan con una politica específica en la C.EE, más allá del Sistema de Preferencias Generalizadas, que no son tan generalizadas, pues como se argumenta más adelante, la distinción entre "paises competitivos" y "paises beneficiarios" permiten discriminar por la vía de la contingentación precisamente a aquellos paises que logran romper con el esquema tipico de especialización de país subdesarrollado (materias primas y productos de escaso valor ańadido).

Por su parte, aunque las relaciones de la CEE se han visto subordinadas a las especiales relaciones de uno $u$ otro país comunitario con determiadas regiones del Tercer Mundo, la jerarquia existente Espana y Portugal no comporte en principio para los paises latinoamericanos una relación especial similar a la que poseen los paises ACP o los del Magreb y el Machrek. 


\section{Situación de las relaciones económicas entre la CEE y América Latina.}

El análisis de los datos cuantitativos de las relaciones económicas cobra sentido a la luz del estudio histórico apuntado más arriba. Con él se pretende ilustrar la evolución de las tendencias de fondo y avanzar una aproximación a los principales problemas planteados en la actualidad.

\subsection{El flujo de mercancias: Evoluclón del Intercamblo comerclal.}

Si el sector exterior de la economía ha sido siempre el elemento clave a la hora de explicar el modelo de desarrollo seguido por los distintos países de América Latina, en la actualidad, el mismo se ha transformado en la llave que puede si no abrir unas mejores perspectivas para las economias latinoamericanas, si al menos evitar la continuación del deterioro. Si hace tan sólo unas décadas el saldo comercial constituía la palanca principal que habría de permitir los procesos de industrialización sustitutiva, la que, a su vez, debía conducir a una menor dependencia respecto del sector exterior, en la actualidad dicho saldo comercial se ha convertido en la variable crítica del proceso de ajuste estructural en el que están sumidos la mayor parte de los países latinoamericanos como consecuencia del endeudamiento externo y de las cargas financieras derivadas de éste.?

En efecto, estos procesos de ajuste auspiciados desde el FMI han generado una dinámica que obliga a los países latinoamericanos a un creciente esfuerzo exportador. Sin embargo, esta necesidad acuciante de exportar más se plantea en una coyuntura poco favorable, caracterizada por la disminución de la tasa de crecimiento del comercio mundial a lo largo de la última década, por el deterioro de los términos de intercambio como consecuencia del descenso en los precios de algunos productos primarios, y por la configuración de un nuevo patrón de especialización tecnológica a escala internacional ante el cual la capacidad de respuesta de América Latina es bien escasa. Todo ello dibuja un cuadro no muy halagüeno para las expectativas comerciales latinoamericanas en relación con las tasas de crecimiento que el sector exportador debería alcanzar para que los procesos de ajuste fueran al menos, más suaves.

7. Goncalves, Reinaldo: Export expansion and balance-of-payments adjustment of developing countries: a long-term perspective. Development and SouthSouth Cocperation. Vol. 1. núm. 1. Diciembre 1985. 
En medio de este panorama, las relaciones comerciales de América Latina con Europa se han deteriorado más rápidamente de to que lo han hecho con otras áreas del mundo. Ello se refleja con claridad en los porcentajes de las exportaciones totales de América Latina hacia otras zonas del mundo, que en el caso de la CEE han retrocedido del $22.4 \%$ en 1973 al $18.8 \%$ en 1986 , así como en el examen de las importaciones según su lugar de origen en donde puede apreciarse asimismo un retroceso de la CEE desde el $21.9 \%$ en 1973 al $17.2 \%$ en 1986 . Estas cifras son ilustrativas si se comparan, además, con los porcentajes que corresponden al mercado norteamericano y a Japón, y es ahi en donde se observa el mayor deterioro de las relaciones comerciales habido con Europa. ${ }^{8}$

Habría que preguntarse por las causas de este deterioro. Indagando en ellas parece claro que las principales obedecen a factores que tienen su origen en la propia dinámica de la CEE. Forzoso es reconocer que el perfil de la oferta exportadora de América Latina no contribuye a aumentar las expectativas de ampliar su cuota de mercado en Europa, pero son los propios cambios introducidos por la estructuración de la CEE, junto a la ya mencionada configuración del nuevo patrón de especialización tecnológica internacional los que más han contribuido a devaluar dicho perfil en un momento, además, difícil para acometer políticas de reestructuración del aparato productivo bajo la presión de la deuda externa.

Entrando a analizar los elementos que, desde el lado de la estrategia de la CEE, han podido contribuir más negativamente a la evolución de las relaciones comerciales con América Latina, destacaríamos los siguientes:

- En primer lugar, la propia evolución del comercio intracomunitario que ha pasado de representar el $35.2 \%$ del comercio total de la CEE en 1958, a significar el $53.6 \%$ en 1985 en to que afecta a las importaciones $y$, en to que se refiere a las exportaciones, los porcentajes han pasado del $37.2 \%$ en 1958 al $55.5 \%$ en $1985 .{ }^{\circ}$ Es evidente que este avance de las relaciones comerciales registradas en el seno mismo de la comu-

8. Las exportaciones hacia Norteamérica han pasado de representar el $37.4 \%$ del total en 1973 a ser el $40.1 \%$ en 1986; por otra parte, las importaciones procedentes del Japón han ascendido del $70 \%$ en 1973 al $8.4 \%$ en 1986. CLEPI: El desafío de la incertidumbre. Informe sobre la economía mundial. Perspectiva latinoamericana. Ed. Nueva Sociedad. Caracas, 1988 p. 191.

- CEE: El comercio exterior de la Comunidad Europea. Documentos. Comisión de las Comunidades Europeas. Bruselas, 1987. 
nidad se ha producido a expensas del comercio con terceros. $Y$, entre éstos, América Latina ha visto como se reducia su participación en las exportaciones extra-comunitarias europeas de un $10 \%$ en 1958 a un $3.4 \%$ en 1985 , y en las importaciones extra-comunitarias de la CEE desde un $11.1 \%$ en 1958 hasta un $6.4 \%$ en $1985 .{ }^{10}$ Es decir, que América Latina ha visto descender su participación en el comercio extra-comunitario de la CEE frente a otras zonas y paises lo que indica que el avance de la construcción europea le ha afectado más agudamente en este terreno.

- En segundo término, la discriminación de América Latina respecto a otros paises en desarrollo en lo que afecta a las ventajas comerciales ofrecidas por la CEE.

En efecto, por razones de la jerarquia interna existente en la CEE ya expuestas anteriormente, y por otras de carácter geopolítico, Europa se ha dotado de unos instrumentos de relación con terceros paises que privilegian el trato con aquellos con los que tiene convenios de asociación como son los ACP y los de la cuenca del Mediterráneo. América Latina cuenta únicamente con el Sistema de Preferencias Generalizadas (SPG) como herramienta a utilizar en su favor en las relaciones comerciales con la CEE.

Sin embargo, el SPG está sujeto en su funcionamiento a serias limitaciones al reproducir la actual División Internacional del Trabajo, con la discriminación de los productos de mayor valor anadido de los denominados "países competitivos", y en el caso específico de América Latina, supone tasas arancelarias más elevadas para aquellos productos en los que América Latina cuenta con ventajas comparativas. La CEPAL ha calculado que mientras una tasa arancelaria promedio aplicada por la CEE a las exportaciones de América Latina se situaría en torno al $2.6 \%$, la misma resulta inferior al $1 \%$ para los paises de otras áreas del mundo como Africa o Asia. ${ }^{11}$

10. SELA (Sistema Económico Latinoamericano): América Latina en la Economia Mundial: Problemas y perspectivas. Siglo XXI, México 1987 p. 63.

11. CEPAL: El proteccionismo de los paises industrializados: estrategias regionales de negociación y defensa. CEPAL LC/R. 500 Santiago de Chile, 1986. Citado en Gongalves, Reinaldo y De Castro, Juan A: El proteccionismo de los paises industrializados y las exportaciones de América Latina. El Trimestre Económico No. 222. México, 1989. 
- Intimamente ligada a la anterior se encuentra la importancia creciente de las medidas no arancelarias como restricciones al comercio. Esta práctica, que parece constituir la respuesta más patente al rápido incremento de las exportaciones de los países en desarrollo durante la década de 1970, afecta de manera muy especial a América Latina. Así, el $21.7 \%$ de las exportaciones latinoamericanas a la CEE están sujetas a restricciones no arancelarias, porcentaje que es menor para el caso de las exportaciones dirigidas a EE.UU. (18.9\%) o a Japón $(14.2 \%)^{12}$. La mayor parte de estas restricciones son de carácter cuantitativo y se refieren a cupos, licencias, pronibiciones, programas de control voluntario de las exportaciones, etc.

Observando el impacto de las medidas no arancelarias en unos $u$ otros sectores exportadores, se deduce que estas medidas, en lo referente a la CEE, afectan principalmente a aquellos más "sensibles" tales como el hierro y el acero, los textiles o el calzado procedentes de América Latina. ${ }^{13}$

- En cuarto lugar, es preciso hacer mención a la Política Agrícola Común (PAC) como otro de los elementos que directa e indirectamente han incidido en el declive de las relaciones comerciales entre Europa y Latinoamérica. Los efectos de la PAC han sido de dos tipos para la producción agropecuaria latinoamericana: Por un lado están aquellos de carácter proteccionista, al cerrarse el mercado europeo para un cierto número de productos tradicionalmente exportados por América Latina y ser sustituidos éstos por la propia producción comunitaria. $Y$, por otro, es preciso senalar que la PAC ha llevado a una creciente producción de excedentes y a una mayor participación y concurrencia de la CEE en los mercados internacionales que tiende a desplazar a América Latina y otros paises de posibles mercados atternativos, afectando al mismo tiempo la estabilidad de los precios agrícolas con las consiguientes repercusiones en la producción.

Todo ésto es consecuencia de la diferente evolución habida por la producción y el consumo de productos agrícolas en los países de la CEE desde que comenzó a implantarse la PAC. Así,

12 Gongalves, Reinaldo y De Castro, Juan A.: El proteccionismo de los países industrializados y las exportaciones de América Latina El Trimestre Económico No. 222. México, 1989 p. 451. op. cit. p. 452. 
mientras la producción ha mantenido un crecimiento sostenido en torno al $2 \%$ anual, el consumo ha crecido apenas un $0.5 \%$, to que ha dado lugar a los mencionados excedentes y a una política de subsidios para la exportación con el fin de colocarlos en los mercados exteriores.

\subsection{El flujo de capltales.}

Si los flujos comerciales reflejan la pérdida de importancia creciente de latinoamérica para los países de la CEE y de ésta para aquellos, los flujos financieros no hacen sino corroborar estas tendencias, con ciertas particularidades para los casos de la R. F. de Alemania y Espana, y en segundo término para Francia.

\subsubsection{La Inversión}

Históricamente, los flujos de inversiones de los países más desarrollados hacia Latinoamerica han sido muy exiguos, salvo en el caso de los Estados Unidos: a principios del siglo $\mathrm{XX}$, tan sólo el $8.5 \%$ de los capitales franceses, el $11.7 \%$ de los ingleses y el $13.7 \%$ de los alemanes se encontraban invertidos en América Lati$\mathrm{na}^{14}$, en abierto contraste con las inversiones extranjeras de los Estados Unidos, dirigidas en su mayor parte hacia América Latina y Canadá.

Si nos fijamos en las inversiones de las firmas multinacionales, en 1969, justo antes del comienzo de la crisis, sólo el $26.4 \%$ de las filiales se encontraban en paises del Tercer Mundo, y dentro de éste, el $47.9 \%$ se situaban en América Latina. En el caso de las multinacionales de paises comunitarios, tan solo las británicas $(31.8 \%)$, francesas $(40.3 \%)$, belgas $(30.3 \%)$ e Italianas $(32.7 \%)$ tenian un porcentaje de filiales en paises del Tercer Mundo superior a la media, es decir, precisamente los paises con una presencia actual o relativamemte reciente de importancia en los paises subdesarrollados. En to que respecta al porcentaje de filiales en América Latina respecto al total del Tercer Mundo, solo Italia (56\%) y la R.F. Alemania (49.9\%) tienen un porcentaje de filiales de multinacionales superior a la media ${ }^{15}$, es decir, justo aquellos paises que carecen de vínculos neocoloniales o de traro especial con los signatarios de Lomé.

14. N. Bujarin: La economfa mundial y el imperialismo Cuadernos de Pasado y Presente, México 1987 pp. 59-62.

15. Datos tomados de W.AA.: La France et to Tiers Monde PUG Grenoble 1979 p. 92. 
Entre 1976 y 1984 el conjunto de países de la CEE realizaron en América Latina el $28.5 \%$ de sus inversiones en paises subdesarrollados, esto es, $\$ 9.841$ millones. Frente a ésto, en el mismo período los Estados Unidos dedicaron a la región el $45 \%$ de sus inversiones en paises subdesarrollados (\$19.779 millones). Este porcentaje sólo es superado por Espana, que por volumen $\$$ \$1.263 millones) sin embargo se sitúa muy detrás de la R. F de Alemania (\$2.827 millones) o de Gran Bretańa (\$2.592 millones, sin contar la inversión de 1984). De los tres grandes bloques de paises capitalistas desarrollados -CEE, EE.UU.-Canadá, y Japón- tan solo Japón se sitúa por debajo de la CEE en su inversión relativa en América Latina en volumen ( $\$ 6.589$ millones), pero no asi en porcentaje de inversión en paises subdesarrollados pues la misma representa en Latinoamérica el $37 \%$ en el periodo considerado.

Por tanto, de estos datos agregados se deduce que América Latina es la región del Tercer Mundo de menos interés relativo para el conjunto de la CEE en materia de inversión directa, lo cual es coherente con el caracter de la Comunidad, que privilegia a las regiones de tradición colonial de los países miembros: la Commonwealth para Gran Bretana, las ex-colonias francesas y belgas.

Si analizamos la estrategia de inversión durante la primera fase de la crisis (década de los 70), comprobamos un comportamiento muy diferente entre Estados Unidos y Gran Bretaña por una parte, y la RFA y Francia por otra: mientras aquellos han privilegiado los paises subdesarrollados como destino de sus inversiones, pues éstas han crecido más rápido que las dirigidas hacia los países desarrollados (pasando de representar un 18.7\% en el período $1967-73$ a un $36.4 \%$ en $1975-80$ en el caso de los EE.UU. y de un $16.8 \%$ a un $22.6 \%$ en el de Gran Bretana), Francia y la R. F. de Alemania, por el contrario, en la primera fase de la crisis, han privilegiado las inversiones cruzadas entre paises desarrollados, en especial las dirigidas hacia los EE.UU. en el caso de Alemania y el sur de Europa en el de Francia (las inversiones en el Tercer Mundo eran en el periodo $1967-73$ un $\mathbf{4 2 . 5 \%}$ en el caso de Francia y un $27.2 \%$ en el de la RFA, pasado en $1974-80$ a un $22.3 \%$ las francesas y un $20 \%$ las alemanas) $)^{16}$, lo cual se generaliza a partir de 1982 . En todo caso, estas cifras nos muestran que el Tercer Mundo juega un papel marginal en la construcción comunitaria, habida cuenta

16. Datos on AA.W.: Nationalisations ot intemationalisation. Stratégies des multinationales francaises dans la crise. Económica, París 1983 p. 53. 
del papel predominante de Francia y la RFA en la construcción y diseño del espacio común europeo.

Con todo, en relación con América Latina, el caso de la R. F. de Alemania requiere una consideración aparte: su temprana pérdida de territorios coloniales, además de lo exiguo de éstos, ha condicionado el que el capital alemán esté tradicionalmente volcado hacia los países centro-europeos y eslavos como territorios de expansión tradicional. Pese a ello, sus inversiones en América Latina han sido de cierta importancia en México hasta la I GM, y actualmente lo son en Brasil.

Este último país ocupaba a principios de los anos 80 el primer lugar entre los receptores de la ayuda al desarrollo de la R. F. de Alemania desde mediados de los anos 60 , el segundo beneficiario de la ayuda técnica, el décimo de la ayuda financiera y el principal receptor de las inversiones extranjeras en paises subdesarrollados, $y$ el quinto de las inversiones en el extranjero totales alemanas, tras los Estados Unidos, Paises Bajos, Francia y Suiza. ${ }^{17}$

Brasil ha recibido el mayor porcentaje de inversiones extranjeras entre los pertenecientes al Tercer Mundo, lo que explica que cerca del $45 \%$ de las ventas locales de bienes manufacturados en 1977 fuesen realizadas por empresas bajo control extranjero. ${ }^{18}$ De ias inversiones extranjeras, los EE.UU. aportan un tercio de los haberes, mientras que la R. F. de Alemania aparece en segundo lugar, con un $13 \%$ en 1984, seguida por Japón con un $9 \%$.

En general, las inversiones alemanas en el Tercer Mundo, a diferencia de las inversiones francesas, no están concentradas geográficamente, sino económicamente en aquellos países que han alcanzado un cierto nivel de industrialización. Los inversores alemanes muestran un interés cierto en los países con amplios mercados, con un grado de diversificación importante en las inversiones: servicios (turismo), sectores químico y siderúrgico, automóvil, industrias metalmecánicas... El capital germano ha sabido aprovechar los "huecos" dejados por otros países en sus áreas de influencia, por ejemplo desarrollando la energía atómica en Brasil, cuando los Estados Unidos, por motivos estratégicos, se negaban a otorgar dicha tecnología a los militares brasilefios.

17. Tomado de datos recogidos en A. M. Le Gloannec: Transfert de Technologie: la stratégie allemande La Documentación Francaise, París 1983 (varios cuadros).

18. Banco Mundial: Informe sobre el Desarrollo en el Mundo 1985 p. 142. 
Las multinacionales francesas son las que presentan una tenden cia relativa más acentuada a implantarse en el Tercer Mundo. La década de los 60 es un período en que se acentúa la inversión en . América del sur, de modo que por ejemplo Renault fabricaba en 1975 en Latinoamérica el $12.3 \%$ de sus vehiculos producidos en el exterior, y el $69.8 \%$ de los producidos en el Tercer Mudo. Sin embargo, las preferencias de inversión del capital francés en el Tercer Mundo se orientan claramente hacia la cuenca del Mediterráneo, como consecuencia de sus relaciones históricas y económicas con el norte y el occidente de Africa - no es de escasa importancia el que Africa sea dentro del Tercer Mundo el principal cliente de la industria militar francesa-.

Una encuesta de 1981 sobre los motivos de implantación en el extranjero ${ }^{19}$, muestra como la presencia en el mercado es el principal motivo en todo tipo de destino de las inversiones, pero pierde importancia relativa cuanto más atrasado es el pais: principal motivo en el $72 \%$ de las inversiones en los Estados Unidos, $64 \%$ en las destinadas a los demás paises desarrollados, $58 \%$ en las que se dirigen a los NPI y $45 \%$ en las orientadas a otros paises subdesarrollados. Por el contrario, aumentan significativamente en importancia relativa respecto a los motivos de inversión en los países desarrollados la protección de los productores locales por los poderes públicos, y a continuación la reducción de la demanda en Francia. Es decir, el acceso al mercado local y la política proteccionista por un lado, y el carácter "aliviador de coyuntura" por otro, definen los principales motivos de las inversiones extranjeras en el Tercer Mundo por parte de las multinacionales francesas. Esto nos indica que, en la medida que dichos motivos sean generalizables a todos los paises comunitarios, los propios países latinoamericanos tienen una gran responsabilidad en generar el clima adecuado para favorecer una mayor presencia económica de la CEE en la región, que pasaria por incrementar la capacidad de consumo de la población y el desarrollo de políticas proteccionistas selectivas... ijusto to contrario de lo que está provocando la aplicación de las políticas de ajuste!

Diversos estudios han demostrado que las multinacionales europeas mantienen en Latinoamérica un comportamiento algo diferente al de las de origen norleamericano; por ejemplo, las empresas de la electrónica transigen con la política nacionalista del

18. En AA. W.: Nationalisations et internationalisation... op. cit. pp. 93-101. 
gobiemo brasileno hacia el disefio, producción y comercialización de micro y minicomputadoras, aceptando participar en el mercado de los productos de gama más alta, a diferencia de la actitud de boicot y presión de IBM. Otro ejemplo podría ser la industria automovilistica en Venezuela, donde las companias europeas Renault, Volkswagen, Fiat y Daimler-Benz, bien han establecido joint-ventures 0 concedido licencias de ensamblaje a companias de propiedad nacional; por su parte, GM, Chrysler y Ford, también presentes en la economía venezolana, son subsidiarias cuya propiedad está totalmente en manos de las casas matrices. ${ }^{20}$

Quizá se podria concluir que las companias originarias de la CEE tienen una posición más flexible a la hora de negociar bajo las premisas de la soberania nacional de los paises latinoamericanos. Aunque ciertamente las estrategias de inversión de las multinacionales se establecen a partir de un panorama internacional de realidades y cambios que se situan al margen del control de los gobiernos particulares, la aceptación mayor o menor de ciertos condicionamientos de política económica global es un factor importante en la cualificación de las inversiones, que debería ser tenido en cuenta por los propios gobiemos latinoamericanos, a la hora de planificar sus estrategias de atracción de capitales exteriores.

\subsubsection{El endeudamlento externo}

Los restantes flujos de capital, en especial los créditos y la ayuda al desarrollo, es lógico que tengan una orientación similar a los flujos de capital y mercancias.

Es sabido que los flujos financieros internacionales transitan, en su casi totalidad, por los circuitos bancarios. En este sector, la presencia de las multinacionales norteamericanas es aún más importante que en el sector productivo, pues realizan en torno a la mitad de las operaciones bancarias internacionales. Si tenemos en cuenta que en América Latina se situaban en 1979 el 15.7\% de las implantaciones extranjeras de la banca francesa, frente al $39 \%$ en el resto del Tercer Mundo, o el $17 \%$ de las alemanas, frente al $34 \%$ en el resto del Tercer Mundo'1, se entiende que, como indican Hillcoat y Quenan "el liderazgo de los bancos estadounidenses, en relación con los deudores, no es contestado por parte de los ban-

20. Fernando Coronil y Julie Skurski: Reproducing dependency: auto industry and petrodollar circulation in Venezuela International Organization 36, 1 invierno 1982.

21 AA.W.: Nationalisations et internationalisations... op. cit. p. 67 
cos de otros paises"22. Esto es lógico, cuando analizamos quienes son los acreedores de la deuda latinoamericana. Como senalan los mismos autores, los bancos británicos, franceses, alemanes y espanoles no representaban en junio de 1985 más que el $29.2 \%$ de la deuda de los diez paises latinoamericanos más endeudados con los bancos comerciales, frente al $36.3 \%$ de los bancos estadounidenses. Tan sólo los británicos (en especial el Midland Bank), con un $\mathbf{1 5 . 4 4 \%}$, tenian comprometida más de la mitad de la deuda de latinoamérica con Europa. ${ }^{23}$ Los compromisos de los cuatro paises latinoamericanos más endeudados en 1985 (Brasil, México, Argentina y Venezuela) tenian una deuda con bancos alemanes de 12.86 mil millones de dólares, cifra muy alejada de los 60 mil millones adeudados a los 16 mayores bancos norteamericanos. Como se indica en el informe mensual de enero de 1987 del Banco Federal Alemán, la tendencia de la banca privada alemana es a disminuir su cuota de participación en los compromisos financieros de América Latina, y en general del Tercer Mundo. ${ }^{24}$

Esta tendencia se observa para el conjunto de la deuda pública a largo plazo: mientras que la deuda en dólares paso del $65.1 \%$ al $76.3 \%$ entre 1975 y 1985, la deuda en divisas de paises comunitarios ha disminuido drásticamente de porcentaje: del $8.8 \%$ al $4.8 \%$ la contraria en marcos alemanes, del $4.3 \%$ al $2.9 \%$ la deuda en francos franceses, o del $5.6 \%$ al $1.5 \%$ en libras esterlinas. ${ }^{25}$ Si consideramos que por ejemplo el marco alemán en tanto que divisa de reserva ocupa el segundo lugar tras el dolar, con una cuota del $14.5 \%$ en 1985, comprobamos que la participación alemana en el endeudamiento externo es muy inferior al potencial de su moneda. La participación del capital financiero de los países comunitarios en las actividades especulativas a escala mundial es ciertamente importante, aunque su participación en la concesión de créditos a América Latina es muy inferior al potencial económico y financieros

Guillermo Hillcoat y Carlos Quenan: La banca siempre gana. Estrategias de los acreedores frente a la deuda externa. Nueva Sociedad 94, marzo-abril 1988 pp. 128-129.

23. Esto es un efecto lógico del origen de la deuda y del circuito del capital financiero mundial en la década de los 70: los excedentes de dólares de los palses exportadores de petroleo a principios de la década, (petrodólares), se canalizaban a través de la City (eurodólares), o vía multinacionales del petroleo, a través de los bancos norteamericanos

24. Citado on Raúl Rojas (ed.): Die Armut der Nationen. Handbuch zur Schuldenkrise von Argentinien bis Zaire Rotbuch Verlag. Berlin 1987 p.73

Banco Mundial: Informe sobre el Desarrollo en el Mundo 1985 p. 26. 
de la Comunidad.

La actitud de los acreedores comunitarios de América Latina fluctúa entre el reconocimiento de la imposibilidad de recuperar la deuda pendiente y por tanto la adopción de las medidas correspondientes para cubrir los probables fallidos, y el alineamiento tras los organismos multilaterales dominados por los EE.UU. encargados de imponer las políticas de ajuste orientadas a canalizar recursos hacia el servicio de la deuda.

En todo caso, hay que tener en cuenta que el capital financiero es la fracción del capital más autónoma respecto a la regulación estatal y por tanto comunitaria, y su estabilidad -la estabilidad de su negocio- depende de la de los grandes bancos norteamericanos altamente comprometidos con la deuda latinoamericana. Por tanto, las políticas de ajuste y los sucesivos planes Baker, Brady... encuentran en los capitales financieros europeos una actitud similar a la de la banca norteamericana. La posibilidad de la CEE de influir decisivamente en el curso del endeudamiento del Tercer Mundo, y en primer lugar de América Latina, es ciertamente limitada desde el punto de vista económico, y sería en el terreno de la presión política y social donde se podria avanzar hacia una actitud más comprensiva de las reales dimensiones del problema en el continente latinoamericano.

\subsubsection{La ayuda al desarrollo}

Como ya se ha planteado anteriormente, la política exterior de la CEE, en lo que afecta al Tercer Mundo, es refiejo de una jerarquia de intereses internes. jerarquia que determina las prioridades relacionadas con las áreas de influencia de los países más fuertes de la Comunidad. La Ayuda al Desarollo no escapa tampoco a esta jerarquización por lo que la misma se orienta, también en este caso, hacia los paises ACP. De hecho, América Latina sólo ha venido percibiendo en los últimos años una cantidad muy pequeña de los fondos destinados por la CEE para Cooperación al Desarrollo, y hasta 1976 los países no asociados en vias de desarrollo no habian tenido otra asignación comunitaria que la referida a Ayuda alimentaria.

Tras la dotación en este año de 1976 de una partida presupuestaria específica orientada a la Asistencia Financiera y Técnica a los Paises No Asociados, el esquema de prioridades de la Ayuda al Desarrollo comunitaria quedó establecido así: En primer término, los paises ACP; a continuación los países mediterráneos (funda- 
mentalmente los paises del Magreb y del Mashrek); y, por último, los Paises No Asociados de América Latina y Asia. Ahora bien, dentro de este grupo, América Latina sale de nuevo desfavorecida ya que el reparto genérico establece un $75 \%$ para Asia y un $25 \%$ para América Latina.

A partir de ahi, prácticamente nada. Las ayudas que, en forma de subvenciones y créditos, otorga la Comunidad a través del FED (Fondo Europeo de Desarrollo) no alcanzan a América Latina ya que están destinadas a los paises ACP. Lo mismo ocurre con el Banco Europeo de Inversiones, de cuyas líneas si se benefician en cambio los paises mediterráneos. Es decir, que la discriminación de América Latina en las políticas de Ayuda al Desarrollo de la CEE no se limita a la cuantía de la misma sino que tiene la base fundamental en su diferente cualificación.

Desde un punto de vista formal, la Comunidad a firmado en los últimos anos un conjunto de acuerdos con países y grupos de paises latinoamericanos entre los que se encuentran los convenios con Brasil, México y Unuguay, asi como los establecidos con los miembros del Acuerdo de Cartagena y con los paises firmantes del Tratado General de Integración Centroamericana. Estos acuerdos son, por to general, de tipo comercial y económico, y en ellos apenas se alude a la Ayuda al Desarrollo, salvo en los casos de los convenios firmados con el Pacto Andino y con Centroamérica en donde este apecto queda expresamente reflejado en un articulo. En este mismo sentido, resultan muy ilustrativas las conclusiones sobre las relaciones entre la CEE y América Latina aprobadas en el Consejo de Ministros de la Comunidad de 22 de Junio de 1987 en las que las referencias a la Ayuda al Desarrollo se plantean en términos de "continuar la APD hacia América Latina" o de "mejorar" o "aumentar su eficacia", rehuyendo claramente cualquier alusión explicita al incremento de los fondos de dicha ayuda. ${ }^{20}$

Desde el punto de vista cuantitativo, la Ayuda al Desarrollo aportada por la CEE a América Latina y el Caribe supuso en $13.2 \%$ de los fondos presupuestados por la Comunidad para este capitulo en el bienio 1985/86, porcentaje inferior al de los EE.UU. que destinaron a América Latina el $21.5 \%$ de los fondos para Ayuda al Desarrollo. ${ }^{27}$ 
En todo caso, sería incompleto analizar la Ayuda al Desarrollo que Europa dedica a América Latina sin tener en cuenta la cooperación bilateral que llevan a cabo los paises miembros de la CEE que, a su vez, son miembros del CAD. En conjunto, esta cooperación bilateral con los países latinoamericanos representa una cantidad más de diez veces superior a la de la propia CEE. ${ }^{28}$ Por paises, Francia y Alemania son las que dedican sumas más importantes para la Ayuda al Desarrollo dirigida hacia América Latina, siendo también significativa la contribución de los Paises Bajos, no tanto en la cantidad global pero si en el porcentaje ( $19.1 \%$ de la Ayuda global tiene como destino América Latina). En todo caso, ninguno de los paises comunitarios miembros del CAD destina a América Latina una cantidad superior al $20 \%$ de sus fondos para Cooperación al Desarrollo. ${ }^{29}$

Por lo que respecta a la evolución de la Cooperación para el Desarrollo de América Latina desde la CEE, todo apunta al mantenimiento de las tendencias actuales. La Comunidad ha planteado la necesidad de incrementar su ayuda sobre todo hacia aquellos paises menos desarrollados de América Latina pero ello no ha tenido una plasmación en modificaciones sustanciales de los flujos hacia dichos paises. Por otra parte, todo indica que los limites de la Cooperación al Desarrollo en esta zona por parte de la CEE están bastante pertilados: La no formalización de acuerdos preferenciales específicos con los paises latinoamericanos, reduciendo los ámbitos de la cooperación a aspectos muy concretos relacionados con los programas de inversión existentes.

De una manera más general, y refiriendonos globalmente a los flujos económicos entre Europa y América Latina, la perspectiva del mercado único de 1992 arroja nuevas sombras sobre estas relaciones. Las medidas tendentes a crear el mercado único se pueden analizar en dos sentidos: hacia el interior de las fronteras comunitarias se trata de facilitar la libre circulación de bienes, servicios, capitales y, con ciertas restricciones, de trabajo. Hacia fuera del marco comunitario se trata de colocar en situación desventajosa a todos aquellos que pudieran suministrar tales bienes, servicios, capital y trabajo.

28. Estimación realizada a partir de los datos del citado informe de la OCDE.

20. Es preciso recordar que España, país que sí supera este porcentaje, no es miembro del CAD. 


\section{La fuerza de trabajo y el cierre de las fronteras europeas}

El comportamiento de la fuerza laboral en lo que afecta a su movilidad entre unos y otros paises no depende de un hipotético mercado de trabajo a escala mundial inexistente, sino de las migraciones consentidas periodicamente para cubrir situaciones de escasez de mano de obra en determinadas zonas del mundo. Esta es la razón por la que se han sucedido épocas de importantes migraciones y épocas de mayor control de la fuerza de trabajo provenientes del exterior.

Por lo que respecta a Europa, la necesidad de mano de obra provocó una fuerte inmigración provenientes tanto de los paises del sur del continente como de otros de Africa del Norte. Turquía o incluso el Caribe, durante las décadas comprendidas entre 1950 y 1970. La disminución del ritmo de crecimiento de las economias europeas y las transformaciones operadas en el proceso productivo han hecho que, posteriormente, la tendencia se haya invertido y hoy, desde la CEE, se propugnen todo tipo de políticas tendentes a impedir la entrada de nuevos trabajadores extranjeros. En la actualidad, podemos afirmar que la política sobre migraciones se ha convertido en una cuestión central en Europa, al igual que lo es en EE.UU.

A la hora de analizar la problemática de la mano de obra extranjera en la europa comunitaria y en la perspectiva del mercado único de 1992 hemos de distinguir dos aspectos claramente diferenciados: El de su significación estrictamente económica por un lado y el de sus implicaciones políticas por otro.

Por lo que respecta a la primera de estas dos cuestiones senalaremos que la emigración hacia los países más desarrollados constituye un fenómeno que va más allá de la solución de problemas individuales de los propios emigrantes para convertirse en un elemento central de la estrategia de sobrevivencia de familias enteras y sectores sociales que permanecen en los paises de origen. Basandose en cifras del Banco Mundial, Bob Sutcliffe ha estimado recientemente que el conjunto de las remesas enviadas por los emigrantes de todo el mundo a sus países de origen suponen una cantidad sólo escasamente inferior al total de la Ayuda Oficial al Desarrollo.. ${ }^{30}$ Este dato habla por sí sólo de la importancia que dichas transferencias tienen en las relaciones económicas internacionales.

30. Bob Sutcliffe: Nuevas formas de imperialismo en los años 80 (mimeo.) Bilbao, 1989. HEGOA (Centro de Documentación $\theta$ investigaciones sobre Paises en Desarrollo). 
Aunque la Europa comunitaria representa actualmente un mercado de trabajo importante del Norte de Africa o de Turquia, no tiene evidentemente tanta relevancia para la mano de obra proveniente de América Latina, ya que aunque no se conocen cifras exactas, sólo una pequena parte de los más de nueve millones de emigrantes extranjeros que trabajan en paises de la CEE son de origen latinoamericano. En Espana, el pais comunitario con mayor presencia absoluta y relativa de latinoamericanos, éstos representan aproximadamente un $25 \%$ del total de inmigrantes provenientes del exterior. Con todo, no hay que desdehar el alcance que el tema tiene para algunos colectivos en particular. Este es el caso de Colombia, pais del que en los últimos anos han salido centenares de miles de personas como consecuencia de la situación económica, social y política por la que atraviesa el pals. El Dr. Augusto Murillo, psicoanalista colombiano y profesor de la Universidad de Mons, en Bélgica ha estimado en casi cinco millones los colombianos que viven en el extranjero, de los que más de 200.000 vivirian actualmente en Europa. ${ }^{31}$ El cierre de las fronteras europeas significa para éstos y otros miles de latinoamericanos un grave problema de sobrevivencia.

Pero si desde un punto de vista cuantitativo el mercado laboral europeo no tiene la importancia que puede tener el de EE.UU. para los latinoamericanos, desde el punto de vista cualitativo la perspectiva del 92 resulta sumamente preocupante. $Y$ ahl están las implicaciones políticas a las que haciamos referencia.

Por una parte, el cierre de las fronteras europeas va a suponer la declaración formal de ciudadanos de segunda categoría no sólo para los latinoamericanos sino para muchos millones de habitantes del Tercer Mundo que van a tener que obtener un visado incluso para entrar en paises que, como Espana, hasta ahora no los exigian con América Latina.

Por otra parte, la posibilidad de que Europa continúe siendo tierra de asilo para las innumerables victimas de las violaciones de los derechos humanos en América Latina va a ser puesta en entredicho, to que resulta francamente contradictorio con las puertas abientas de par en par a los que han huido en los últimos meses del Este de Europa. Las opiniones aparecidas en la prensa europea sobre la mayor cualificación y docilidad de la fuerza de trabajo proveniente del Este son, en ese sentido sumamente preocupantes.

31. Augusto Murillo: Los Colombianos en Europa. ponencia presentada en el Congreso sobre los Derechos Humanos en Colombia. Ginebra, 1989. 
ror último, las consecuencias políticas que el cierre de las frontoras a los emigrantes está trayendo y puede traer aún para la propia Europa son, cuando menos, inquietantes: el ascenso del racismo y de los grupos neofascistas es un fenómeno visible hoy en todo el continente, hasta el punto de que el Parlamento Europeo encargó una investigación sobre el tema en 1984. Los resultados de esta investigación, publicados en 1985 hablaban a las claras de sentimientos más o menos difusos de xenofobia, de signos cotidianos de desconfianza y de hostilidad hacia los emigrantes, de discriminación incesante en la búsqueda de vivienda y trabajo o en la prestación de servicios, etc. ${ }^{32}$ Europa, la europa de la libertad y de la democracia, corre peligro de convertirse en una zona cerrada o, en todo caso, abierta sólo a otros ciudadanos, también de la $1^{4}$ categoria, provenientes del mundo desarrollado.

Lo que llama poderosamente la atención es la persistente ausencia en todos los análisis sobre el tema, de cualquier referencia a la responsabilidad europea ( $y$ del resto del mundo desarrollado) en las causas que obligan a millones de personas a abandonar sus paises origen por falta de oportunidades para subsistir dignamente. La condición de emigrante forzoso es sumamente dura y ninguna persona que se encuentra en esa situación lo hace por gusto. Pretender cerrar las fronteras a la mano de obra procedente de América Latina y del resto del Tercer Mundo mientras éste se ha convertido en exportador neto de capitales hacia el mundo industrializado puede contribuir a un mayor desarrollo de la insolidaridad y a abrir las puertas a brotes de racismo y xenofobia más y más preocupantes. En el caso de América Latina el tema resulta a la vez irónico si consideramos los grandes contingentes de europeos que emigraron a aquel continente en busca de mejores perspectivas de vida en épocas pasadas.

\section{Las relaciones politicas entre la CEE y América Latina.}

Las relaciones exteriores de la CEE han estado marcadas desde su constitución por lo que algunos han llamado la lógica contradictoria de la construcción europea. Una lógica determinada por el abandono de su protección en manos de EE.UU. tras la segunda guerra mundial, y en un posterior crecimiento económico que le confirió una mayor autonomía política en la esfera internacional, autonomía cuyos límites estaban representados precisamente por la hipoteca militar norteamericana..$^{33}$

32. Parlamento Europeo: Informe de la Comisión de Investigación del ascenso del fascismo y el racismo en Europa. Diciembre 1985. 
La cooperación política entre la CEE y América Latina constituye con todo un fenómeno relativamente reciente y por ello difícil de evaluar con perspectiva suficiente. Hasta hace bien poco, la CEE habla considerado América Latina como zona de influencia exclusiva de los EE.UU. y sólo en la última década se han dado algunos pasos tendentes a mantener una presencia propia, aunque limitada, en este continente. Las principales ideas que han presidido las relaciones entre la CE y América Latina se encuentran recogidas en la comunicación de la Comisión Europea el Consejo de Ministros (27/1/87) y en la Declaración del propio Consejo de Ministros de la Comunidad de 22 de Junio de 1987 sobre "Nuevas orientaciones de la CE para las relaciones en A. Latina" $(22 / 6 / 87)$. En estos documentos se hace referencia a las razones históricas, políticas, económicas y culturales que hacen del fortalecimiento de las relaciones entre ambos continentes un asunto de la mayor importancia. Sin embargo, esa importancia atribuida sobre el papel a las relaciones con América Latina ha tenido mayor reflejo en la retórica de las declaraciones que en la práctica de la colaboración de la CEE con Latinoamérica, pese a que, formalmente, en los últimos años se ha incrementado la cooperación política al tiempo que declinaban las relaciones económicas y comerciales.

Dos han sido los elementos centrales en los que ha venido insistiendo una y otra vez la CEE en sus relaciones con América Latina: los procesos de democratización y las políticas de integración.

El primero de estos dos elementos ha estado presente en casi todas las declaraciones y protocolos firmados tanto por la CEE como por sus paises miembros con paises de América Latina, hasta el punto de condicionar algunos de los programas de cooperación al mantenimiento de instituciones democráticas. También en el caso de Centroamérica, la cuestión de la democratización ha sido unas de las constantes en las declaraciones formuladas por representantes de la CEE sobre los conflictos del Istmo.

Por lo que se refiere a la segunda cuestión, la de los procesos de integración, la misma ha llegado a constituir un emblema caracteristico de las relaciones entre la CEE y América Latina. En efecto, la necesidad y/o conveniencia de los procesos de integración está presente no sólo en los protocolos firmados por la CEE con los palses centroaméricanos y con los paises andinos, sino también en la declaración del

33. Deséglise, Christian: Las relaciones de Europa con América Latina: Ls lógica de sus respectivas actuaciones. Análisis Polltico No. 2. Bogotá, SepDic. 1987 p.75. 
Consejo de Ministros de la Comunidad sobre las relaciones con Anll rica Latina.

Estos dos aspectos (el de la democratización y el de la integración) han sido percibidos y valorados de distinta manera. Asi, aunque ambos representan la existencia de una cierta condicionalidad en las relaciones entre América Latina y Europa, la insistencia en la necesidad de la democracia ha gozado de un consenso generalizado - tal vez por la obvia en un continente gobernado por los militares durante décadas-, en tanto los apremios a la integración han sido considerados en ocasiones como faltos de realismo y hasta como intentos de trasplantar una experiencia que responde a claves y coyunturas históricas my diferentes. Como es bien sabido los procesos de integración atraviesan, en América Latina, por no pocos problemas que han dado lugar a numerosos debates y al surgimiento de una conciencia generalizada sobre la necesidad de replantear y reformular la integración. Además, existe una doble dinámica, la del corto plazo, condicionada por los procesos de ajuste económico y por las estrategias individuales de cada pais frente a sus acreedores, y otra, la del medio y largo plazo, en la que los procesos de integración cobran toda su dimensión e importancia para propugnar un desarrollo efectivo. Pero este medio y largo plazo está condicionado a la resolución de los grandes problemas presentes por lo que resultaria de más utilidad un mayor compromiso de la CEE en su solución que simples llamadas genéricas a la integración.

Pero, más allá de la letra y de las declaraciones, la política de la CEE hacia América Latina ha estado condicionada en su escaso desarrollo por los dos elementos más arriba mencionados: La posición hegemónica de algunos paises mieribros en el seno de la Comunidad, y los límites impuestos por la alianza militar con los EE.UU.

Respecto a la primera de estas dos cuestiones, la misma ha resultado determinante en la discriminación sufrida por América Latina respecto a otros paises en desarrollo, antiguas colonias de Francia o Inglaterra y tuvo una manifestación contundente en el apoyo prestado a esta última durante la guerra de las Malvinas. Por lo que se refiere a los limites impuestos por los EE.UU. para la política europea en América Latina, éstos se han puesto de manifiesto con relativa claridad en los últimos tiempos.

En Centroamérica, el esfuerzo por tener una presencia significativa que contrarrestase el efecto mortifero de la presencia de los EE.UU. en la región y su tratamiento como "patio trasero", que se concretó en la declaración franco-mexicana o en el apoyo a los procesos de Contadora y Esquipulas, sufrió un cierto retroceso a la hora de plasmarse en 
ayudas concretas. Es preciso recordar a este respecto que los $\mathrm{Mi}$ nistros de Asuntos Exteriores centroamericanos presentaron en la reunión de Hamburgo un programa de emergencia por valor de 1431 millones de dólares, ante el que los representantes europeos se limitaron a "tomar nota", según consta en el documento final de la reunión, si bien en los meses siguientes se produjo un sensible aumento de la Ayuda alimentaria.

Por fin, el alineamiento de todos los paises de la CEE, salvo Espaha, en contra del rechazo a la invasión militar y política norteamericana de Panamá, representa un serio revés a la credibilidad política de la CEE entre los paises latinoamericanos y al papel en apoyo de la normalización democrática que podrían jugar los paises europeos occidentales. En este sentido, cabe afirmar que la influencia de determinadas corrientes políticas (en especial de la Internacional Socialista y de la Democracia Cristiana) se hace notar más en ocasiones que la de los propios estados europeos y, por supuesto, que la de la CEE. Y mientras no se avance en la creación de un espacio político europeo, no parece muy factible una modificación significativa en estas tendencias.

\section{Reflexiones finales}

Del conjunto de los temas expuestos se obtiene, a nuestro entender, una panorámica global sobre las relaciones entre Europa y América Latina en la que los rasgos más acusados son aquellos que marcan un progresivo distanciamiento de estas dos realidades tanto en el plano económico como en el político, pese a los gestos y a la retórica desplegados.

Ahora bien, si tuvieramos que sintetizar todo ello en unas breves ideas, to hariamos vinculando éstas a las principales limitaciones y obstáculos que constrinen el desarrollo de estas relaciones. Y estos límites vienen marcados por tres tipos de razones que se han ido desgranando a lo largo de este trabajo.

- En primer término, la propia realidad de la Comunidad Europea, cuya creación y posterior desarrollo obedece a intereses que poco o nada tienen que ver con el establecimiento de un orden económico internacional más justo. $Y$ dentro de esta misma realidad la discriminación de América Latina respecto a otras áreas del Tercer Mundo, como reflejo de la jerarquización intema que funciona, de hecho, en la CEE y en sus relaciones exteriores. 
- En segundo lugar es preciso mencionar la subordinación creciente de la CEE a las políticas de ajuste propugnadas por el FMI y puestas en marcha en casi toda América Latina, las que, en la práctica, frenan las posibilidades para otras políticas de desarrollo.

- $Y$, en último término, la alianza militar mantenida a lo largo de las últimas décadas entre Europa y Estados Unidos ha jugado un papel determinante en la importante ausencia europea en la política latinoamericana, solo quebrada - negativamente- por la guerra de las Malvinas, y por las tímidas iniciativas para Centroamérica, desdibujadas asimismo tras el apoyo implícito mostrado a la invasión de Panamá por parte de los paises comunitarios.

Pero si estos limites siguen operando a la hora de impedir un mayor desarrollo en las relaciones entre Europa y América Latina, un nuevo elemento ha venido a anadirse en los últimos meses a la línea de prioridades de la CEE en política exterior: Nos referimos a los cambios ocurridos en el Este de Europa que abren una nueva expectativa, de dimensiones aún impredecibles, para la economia europea, lo que, sin duda, tendrá -está teniendo ya de hecho- un reflejo en la percepción que desde Europa se tenga de las relaciones Norte-Sur y, muy especialmente, de las relaciones europeo-latinoamericanas.

Esta línea de reflexiones finales obliga sin duda a plantearse el futuro de las relaciones entre Europa y América Latina estrechamente vinculado a las posibilidades de que se modifiquen dichas tendencias de fondo, lo cual pasa por la existencia de una voluntad política en la Comunidad capaz de lograr la autonomia suficiente respecto a los intereses económicos, como para plantear las relaciones con América Latina, y en general con el Tercer Mundo, en un marco diferente al actual.

En este sentido no parece que el entramado institucional actual de la CEE sea el más adecuado para establecer unas relaciones con AL en las cuales el desarrollo económico y el beneficio mutuo sea el motivo impulsor de las mismas, al menos en condiciones de igualdad en los beneficios. Algunos sintomas que avalan esta afirmación: la nueva realidad económica de la Europa unida a partir de 1993 no va a tener una repercusión significativa en las actitudes de la CEE ante los organismos multilaterales de financiación del desarrollo. Tampoco parecen los paises comunitarios dispuestos a otorgar un tratamiento homogeneo a los paises del TM, que contemple únicamente su diferente situación 
estructural, pero no los lazos históricos particulares con uno u otro pais comunitario. La ausencia de una verdadera política comunitaria de ayuda y cooperación al desarrollo se inserta en la crisis más general de las alternativas políticas y económica ante la crisis económica global.

Tomar conciencia de esta situación deberia llevar en AL a la elaboración de estrategias que permiten colaborar conjuntamente en establecer un nuevo marco de relaciones con la CEE. Este objetivo fundamental, sin embargo, tropieza con la ausencia de las condiciones en AL para que se puede dar una relación de colaboración y coordinación de este tipo entre los diferentes gobiernos, dada la heterogeneidad política que manifiestan.

El avance y consolidación de los procesos democráticos parece una condición indispensable para plantear la viabilidad de este objetivo, ya que el mismo requiere un debate democrático que genere un "nuevo pensamiento" en las relaciones entre la CEE y $A L$, en el que se redefina el papel de las organizaciones no institucionales, tanto latinoamericanas como europeas, en el diseno e implementación de las alternativas.

Las nuevas propuestas requeridas deben partir de la constatación de que la promoción desde la CEE de la democracia y el Estado de Bienestar como destino para AL, resultan incompatibles con la defensa de las políticas de ajuste propugnadas por el FMI y la banca internacional, cuya consecuencia más inmediata está siendo el deterioro institucional y un estado de malestar generalizado entre la población latinoamericana. Las CEE no puede exigir nuevas estrategias de desarrollo, de integración económica y de transformación del aparato productivo en AL a la vez que apoya las políticas de ajuste del FMI y la estrategia individual de supervivencia que se deriva de éstas.

Tampoco es aceptable, desde las convicciones democráticas y la defensa de los derechos humanos, la discriminación hacia la fuerza de trabajo proveniente de AL y otros paises del TM cuando la propia América Latina ha transferido en los últimos seis anos 146.000 millones de dólares netos hacia el mundo desarrollado en el que se encuentra la Europa comunitaria.

Si la CEE quiere representar algo más para las grandes mayorias de AL y de todo el TM que un nuevo bloque hegemónico hecho a la medida de la competencia con EE.UU. y Japón, debe tomar en cuenta estas consideraciones. La contribución que se puede hacer desde AL pasa por hacer ver a las fuerzas políticas actuantes en la CEE, que el 
proyecto político de una Comunidad Económica hecha a medida de las necesidades humanas no se puede hacer sin considerar la interdependencia entre el diseno comunitario europeo y en las condiciones de vida de las mayorias populares del planeta. 